
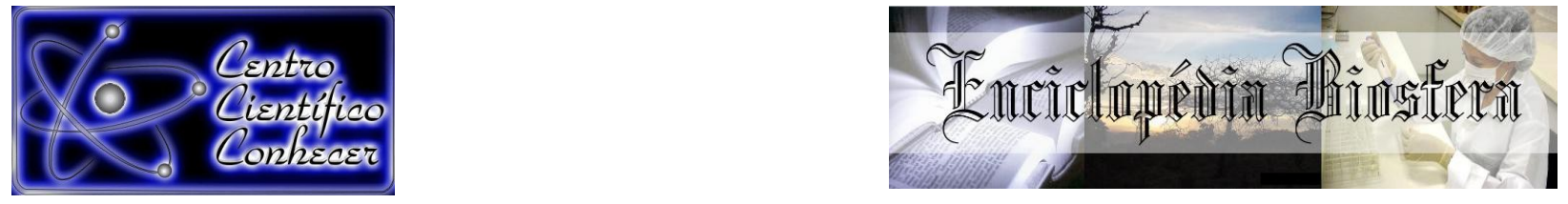

\title{
ANÁLISE ESPACIAL PARA SELEÇÃO DE ÁREA IDEAL À IMPLANTAÇÃO DE POVOAMENTOS FLORESTAIS NO ESTADO DO PARANÁ
}

Verônica Satomi Kazama1, Ana Paula Dalla Corte ${ }^{3}$, Franciel Eduardo Rex², Carlos Roberto Sanquetta ${ }^{3}$

1 Doutoranda em Engenharia Florestal, Universidade Federal do Paraná, Curitiba, PR, Brasil. veronica.kazama@gmail.com

2 Mestrando em Engenharia Florestal, Universidade Federal do Paraná, Curitiba, PR, Brasil.

3 Professor do Departamento de Engenharia Florestal, Universidade Federal do Paraná, Curitiba, PR, Brasil.

Recebido em: 06/04/2018 - Aprovado em: 10/06/2018 - Publicado em: 20/06/2018 DOI: 10.18677/EnciBio 2018A8

\section{RESUMO}

O objetivo deste trabalho foi determinar as áreas ideias para a implantação de povoamentos florestais no Estado do Paraná, conforme os critérios de restrição do uso do solo, declividade e distância da fábrica, utilizando ambiente SIG. A área de estudo foi a microbacia do Rio Miringuava e os dados utilizados desta área foram adquiridos por instituições do estado, AGUASPARANÁ e ITCG. A análise e o processamento dos dados foram realizados no ArcGis versão 10.4. A partir da informação do uso do solo, foi analisado que $71,85 \%$ da área de estudo é considerada restrita aos plantios florestais e $2 \%(107,74$ ha) à inclinação. Foram obtidas quatro classes de custo de distância, nas quais, foram cruzadas com as classes de uso do solo e declividade ideais para plantio e resultaram em 10 classes distintos. Dessas classes, observa-se que 18\% (793,23 ha) está nas classes de melhores condições para implantação de povoamentos florestais: baixa declividade e baixo custo de distância. Conclui-se que a metodologia do presente estudo permitiu identificar as áreas aptas para implantação de povoamentos florestais de forma ágil. O ganho no processamento e na obtenção dos resultados se deu por meio da obtenção de dados pré-processados.

PALAVRAS-CHAVE: atributos do solo; geoprocessamento, plantios florestais.

\section{SPACE ANALYSIS FOR THE SELECTION OF AN IDEAL AREA FOR ESTABLISHMENT OF FOREST PLANTATIONS IN PARANÁ STATE}

\section{ABSTRACT}

The objective of this search was to determine the ideal areas for implantation of forest in the State of Paraná, according to the criteria of restriction of land use, declivity and distance from the factory, using GIS environment. The study area was the Miringuava River basin and data from this area were acquired by state institutions, AGUASPARANÁ and ITCG. Data analysis and processing were accomplished in ArcGis version 10.4. From the soil use information, it was analyzed that $71.85 \%$ of the study area is considered restricted to forest plantations and $2 \%$ (107.74 ha) to the slope. Four classes of distance were obtained, in which they were crossed with classes of soil use and slope ideal for forest plantation and resulted in 10 different classes. Of these classes, it is observed that $18 \%(793,23 \mathrm{ha})$ is in the best conditions for the implantation of forest stands: low slope and low cost of 
distance. It is concluded that the methodology of the present study allowed the identification of suitable areas for the implantation of forest plantations in an agile way. The gain in processing and in obtaining the results was obtained through the obtaining of pre-processed data.

KEYWORDS: forest plantations; soil attributes; geoprocessing.

\section{INTRODUÇÃO}

Atualmente, a indústria brasileira de árvores plantadas é reconhecida mundialmente por se desenvolver de forma sustentável, competitiva e inovadora (IBÁ, 2017). Com finalidade a diversos produtos, as árvores plantadas no Brasil somaram uma área de 7,84 milhões de hectares, com um crescimento de 0,85\% em relação ao último ano base calculado (2016-2017) (SNIF, 2017).

Dentre os estados brasileiros, o Paraná recebe destaque por obter a maior área de plantio de pinus (672.607 hectares), a segunda espécie de maior extensão de área plantada (1,6 milhão de hectares) no país, que perde apenas para o eucalipto. E esta última espécie, é também outra com uma representativa extensão de área plantada no Paraná, totalizando com 294.050 hectares (IBÁ, 2017). Além disso o Estado é considerado o maior exportador de produtos advindos de madeira de árvores plantadas, com um montante somada em US\$ 1.839.446.548 (SNIF, 2017).

Neste cenário favorável do setor madeiro para o Estado do Paraná, que fomenta a expansão das indústrias florestais, é crescente necessidade por matéria prima para atender este mercado tão expressivo (APRE, 2018). Isto é, inevitavelmente poderão ser requeridos a aquisição de mais áreas para a implantação de novos povoamentos florestais.

No entanto, a escolha destas áreas não se consiste em uma tarefa simples, pois se requer uma análise detalhada de uma série de fatores que influenciam na rentabilidade de uma empresa, nas quais podem ser citados: a) distância entre a fábrica e a fonte de matéria prima, visto que o transporte é um dos componentes do custo logístico que representa o maior valor (ALVES et al., 2013); b) relevo do terreno, uma vez que a produtividade das máquinas é afetada (LEITE et al., 2014) e consequentemente a colheita da madeira em conjunto com o transporte são afetados também e em termos econômicos dentro da cadeia produtiva da madeira, estes dois fatores representam em torno de $50 \%$ ou mais do custo final da madeira posto na indústria (MACHADO, 2014; FERREIRA et al., 2017).

Para auxiliar nesta problemática, a utilização de geotecnologias tem papel fundamental para viabilizar a tomada de decisão florestal (EMMERT et al., 2010; LIMA et al., 2011; AKGUL et al., 2017). O uso de um Sistema de Informação Geográfica (SIG) pode ser muito eficiente por possuir algoritmos capazes de efetuar análises de custos com relação às distâncias de um determinado ponto de interesse, como por exemplo uma fábrica para as áreas de plantio. Neste sentido, o presente trabalho tem como objetivo a determinação de áreas ideais para implantação de povoamento florestais para estado do Paraná de forma rápida, garantida pelo processamento prévio do banco de dados fornecidos para o estado, e de forma precisa por utilizar o apoio de ferramentas de SIG.

\section{MATERIAL E MÉTODOS}

\section{Área de estudo}


O presente estudo foi realizado na microbacia do rio Miringuava (16.130,32 ha) localizada no município de São José dos Pinhais, do Estado Paraná (PR) (Figura 1). A microbacia pertencente a sub-bacia do Alto Iguaçu.

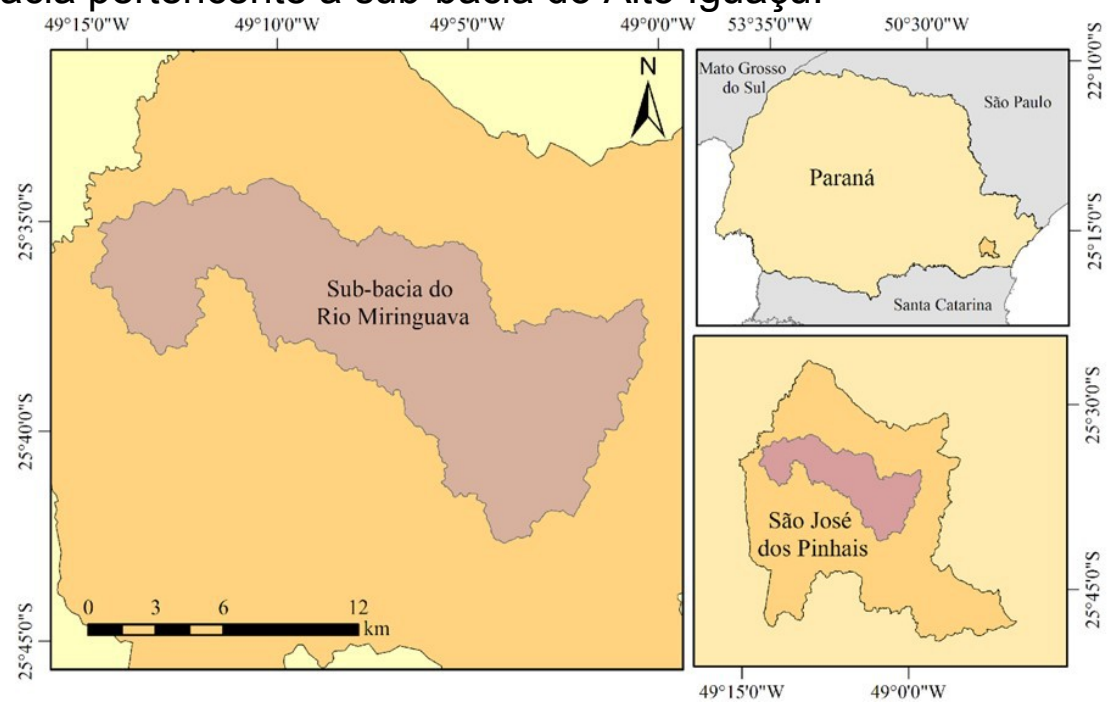

FIGURA 1. Localização da microbacia do Rio Miringuava, em São José dos Pinhais, PR. FONTE: Autores (2018)

\section{Obtenção dos dados}

Os dados utilizados do presente trabalho foram: delimitação das microbacias da sub-bacia do Alto Iguaçu, classificação do uso do solo (Figura 2A), em escalas 1: 20.000 e 1:10.000 respectivamente, adquiridos pelo Instituto das águas do Paraná (AGUASPARANÁ, 2018); formação fitogeográfica (Figura 2B) declividade do solo (Figura 2C) e hidrografia (Figura 2 D), em respectivas escalas 1:50.000, 1:500.000 e 1:250.000, obtidas pelo Instituto de Terras, Cartografia e Geologia do Paraná (ITCG, 2018).

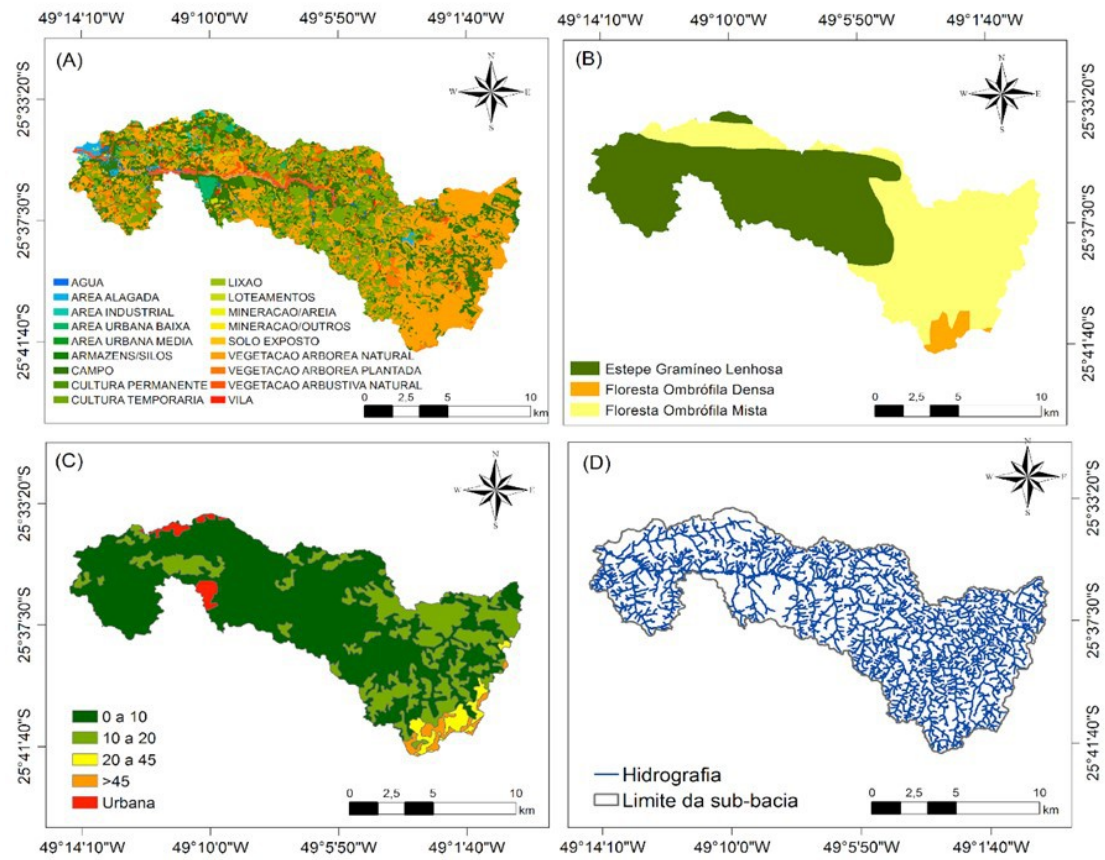

FIGURA 2. Informações utilizadas para o processamento dos dados. Em que: (A) Mapa de classificação do uso do solo; (B) Mapa de formação fitogeográfica; (C) Mapa de declividade do terreno; (D) Mapa de hidrografia. 
FONTE: AGUASPARANÁ (2018); ITCG (2018); SUDERHSA (2000)

Todos os arquivos apresentam formato vetorial, nas quais já apresentavam um processamento de classificação pelas instituições fornecedoras dos dados. Todos os dados digitais foram estruturados em uma Geodatabase, onde todos os atributos das camadas de informações utilizadas no processamento foram vinculados a esta.

\section{Análise espacial}

A análise espacial foi realizada no software ArcGis 10.4. As camadas de informação adquiridas foram referentes a sub-bacia do Alto Iguaçu, e estas foram recortados conforme a microbacia do Rio Miringuava. Em seguida, a análise foi dividida em três etapas para a obtenção de uma área ideal à implantação de um povoamento florestal. Na primeira etapa foi efetuada a classificação do uso do solo, na segunda, a classificação da declividade e por último, a classificação do custo distância com relação a uma fábrica hipotética. Os passos seguidos para se chegar no objetivo podem ser observados na Figura 3, sendo que:
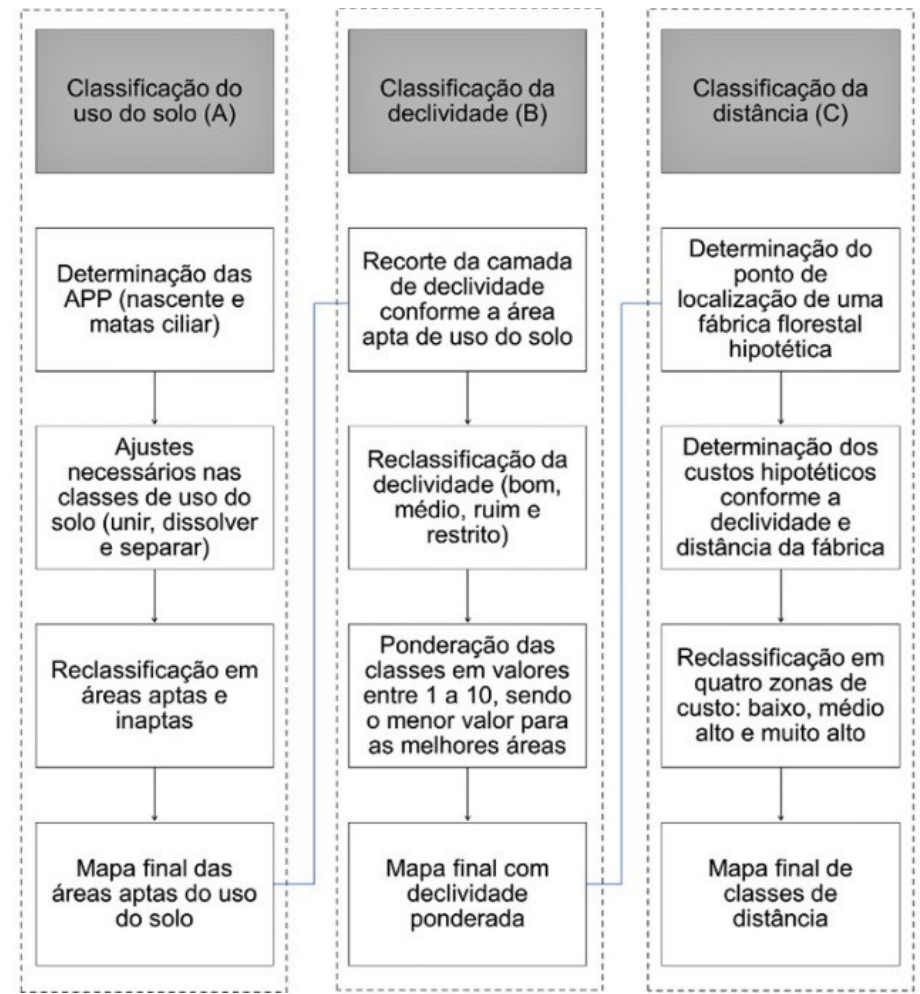

FIGURA 3. Etapas para a análise de decisão áreas ideais para implantação de um povoamento florestal na microbacia do Rio Miringuava, São José dos Pinhais, PR. Em que: (A) etapa de classificação do uso do solo, (B) etapa de classificação de declividade, (C) etapa de classificação do custo de distância conforme a melhor área para localização de plantio florestal na área de estudo.

FONTE: Autores (2018)

\section{Etapa 1) Classificação do uso do solo}

Nesta etapa, foram utilizadas as classes de uso do solo (AGUASPARANÁ, 2018) da área de estudo, nas quais foi verificada a necessidade da identificação das áreas de preservação permanente (APP), e para tal utilizou-se a camada de informação da hidrologia e a ferramenta buffer, sendo projetada um comprimento de 
$30 \mathrm{~m}$ de cada lado para os rios e $50 \mathrm{~m}$ para as nascentes da APP. Em seguida, a camada de APP foi unida com a camada de uso do solo. As linhas interiores aos limites das APP, geradas pela união das camadas que contém polígonos, foram dissolvidas por serem desnecessárias na análise. As técnicas utilizadas de buffer, de unir e de dissolver se encontram entre as ferramentas do Geoprocessing.

Em seguida, no intuito de verificar as áreas de vegetação nativas na microbacia, camada de uso do solo foi cruzada com a informação dos limites das formações fitogeográficas do Estado do Paraná (ITCG, 2018). Em que, foi observado que a classe de uso do solo "campo", por meio classe fitogeográfica "estepe" (campo nativo), continha áreas de campo não nativo, então houve a subdivisão em duas classes distintas: "campo" e "campo nativo".

Após estes ajustes, distinguiu-se as classes de uso e ocupação em áreas restritas e não restritas para implantação de um povoamento florestal como demonstrado na Tabela 1.

TABELA 1. Classes de restrição quanto ao uso do solo na microbacia do Rio Miringuava, São José dos Pinhais, PR.

\begin{tabular}{cccc}
\hline $\mathrm{n}$ & Classes de uso do solo & Áreas restritas & $\begin{array}{c}\text { Áreas não } \\
\text { restritas }\end{array}$ \\
\hline 1 & Água & $\mathrm{x}$ & \\
2 & Área alagada & $\mathrm{x}$ & \\
3 & Área industrial & $\mathrm{x}$ & \\
4 & Área urbana baixa & $\mathrm{x}$ & \\
5 & Área urbana média & $\mathrm{x}$ & \\
6 & Armazéns/silos & $\mathrm{x}$ & $\mathrm{x}$ \\
7 & Campo & $\mathrm{x}$ & $\mathrm{x}$ \\
8 & Campo nativo & & \\
9 & Cultura permanente & $\mathrm{x}$ & \\
10 & Cultura temporária & $\mathrm{x}$ & \\
11 & Lixão & $\mathrm{x}$ & \\
12 & Loteamento & $\mathrm{x}$ & $\mathrm{x}$ \\
13 & Mineração/areia & $\mathrm{x}$ & \\
14 & Mineração/outros & & \\
15 & Solo exposto & $\mathrm{x}$ & \\
16 & Vegetação arbórea nativa & $\mathrm{x}$ & \\
17 & Vegetação arbórea plantada & $\mathrm{x}$ & \\
18 & Vegetação arbustiva nativa & Vila & \\
19 & APP & & \\
20 & & & \\
\hline
\end{tabular}

FONTE: AGUASPARANÁ (2018); SUDERHSA (2000)

\section{Etapa 2) Classificação da declividade:}

Nesta etapa, considerou-se apenas as áreas aptas conforme a camada de uso do solo. Nas quais, destas áreas, foram reclassificadas considerando a inclinação máxima de: $50 \%\left(27^{\circ}\right)$ para movimentação de maquinários florestais mais utilizados na colheita florestal, como harvester e forwarder; $10 \%\left(6,35^{\circ}\right)$ para empilhamento das toras nos pátios de estocagem (LIMA et al., 2011); e 8 a $10 \%$ para estradas florestas (ROCHA et al., 2007).

Conforme tais informações sobre a inclinação e as classes já existente do ITCG a reclassificação foi denominada de baixo $\left(0\right.$ a $\left.10^{\circ}\right)$, médio $\left(10\right.$ a $\left.20^{\circ}\right)$ e alto $(20$ 
a $45^{\circ}$ ) e restrito $\left(>45^{\circ}\right)$. Em seguida, as classes foram ponderadas com valores variando de 1 a 10, considerando 1 à melhor área e 10 à pior área para movimentação de maquinários de colheita e transporte florestal (LIMA et al., 2011; ROCHA et al., 2007), ou seja, para implantação florestal (Tabela 2).

TABELA 2. Classes de declividade na microbacia do Rio Miringuava, São José dos Pinhais, PR.

\begin{tabular}{ccccc}
\hline Classe do ITCG & & \multicolumn{3}{c}{ Reclassificação } \\
\cline { 1 - 3 } \cline { 4 - 5 } Inclinação $\left(^{\circ}\right)$ & Classe & Cor & Peso \\
\hline 0 a 10 & & Baixo & Verde & 1 \\
10 a 20 & Médio & Amarelo & 3 \\
20 a 45 & & Alto & Laranja & 6 \\
$>45$ e Área urbana & & Restrito & Vermelho & 10 \\
\hline
\end{tabular}

FONTE: ITCG (2018)

\section{Etapa 3) Classificação da distância:}

Para efetuar esta etapa foi utilizada a função Cost Distance da ferramenta do Spatial Analyst Tools. Esta função calcula a partir de um ponto de origem uma superfície de custo de distância para cada célula (ESRI, 2018). Neste trabalho, foi considerada como superfície de custo a camada de declividade ponderada, já que os menores valores de declividade, por sua vez, representam menor dificuldade para o tráfego e operação de máquinas, consequentemente representam menores custos.

Enquanto que o ponto de origem foi uma fábrica hipotética, com a localização determinada de forma aleatória pela ferramenta Create Randon points. De acordo com o ponto da fábrica e a superfície de declividade, foi gerada então uma camada de informação de custos, nas quais foram classificadas em 4 zonas de baixo, médio, alto e muito alto.

Por final, foi sobreposta a camada de classificação da declividade sobre a camada de classificação do custo de distância da fábrica e, assim, obteve-se as áreas ideias para implantação de povoamento florestais conforme estes atributos, isto é, as áreas de menor declividade e em áreas de classe com menor custo.

\section{RESULTADOS E DISCUSSÃO}

O resultado da classificação do uso do solo é observado espacialmente, na Figura 4, com as áreas somadas em hectares, na Tabela 3. Nesta, verifica-se que a maior porção da área de estudo, 71,85\% (11.590,65 ha), encontra-se na classe de área restrita, isto se deve ao fato da microbacia do rio Miringuava ser constituída de diversas classes ocupadas por um uso consolidado e/ou destinado à conservação, sendo assim inapropriadas para implantação de plantios florestais. 


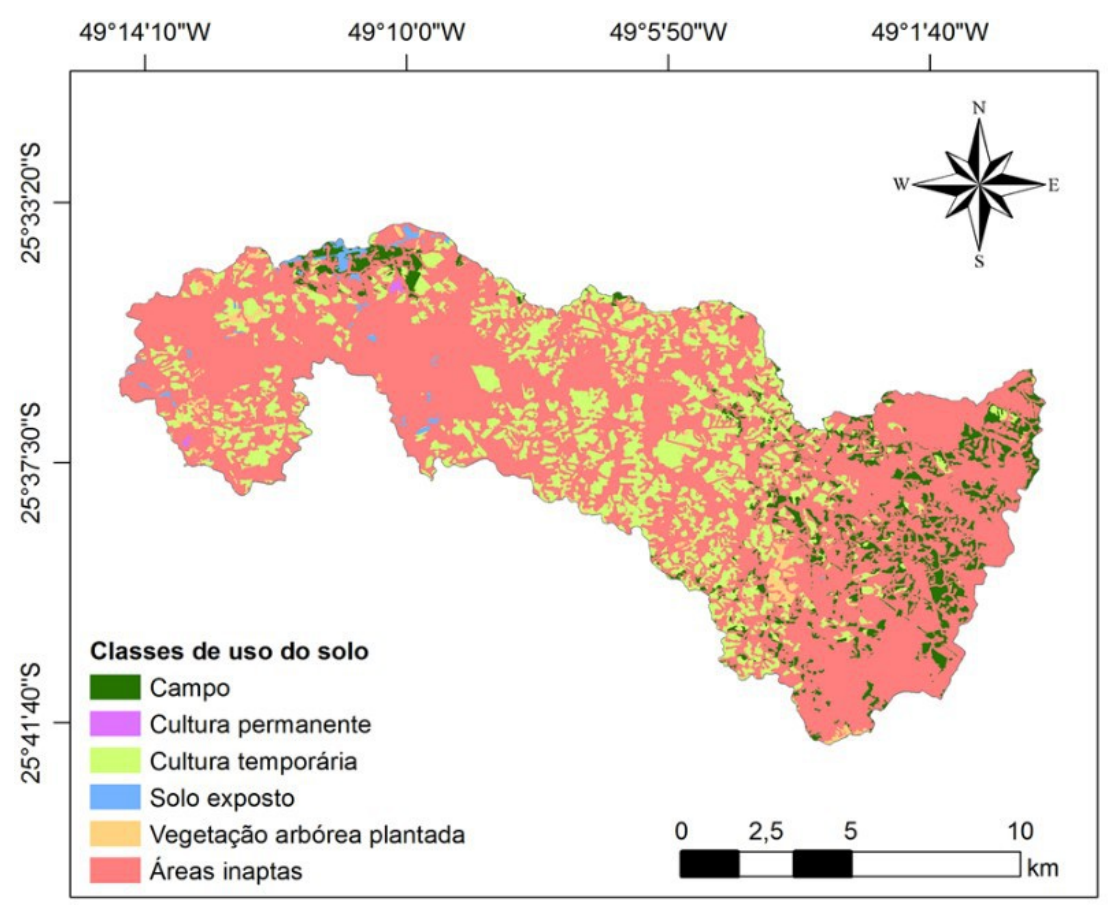

FIGURA 4. Representação das classes de uso do solo quanto a aptidão para um plantio florestal, na microbacia do Rio Miringuava, São José dos Pinhais, Paraná.

FONTE: Autores (2018)

TABELA 3. Área das classes de uso do solo quanto a aptidão para um plantio florestal, na microbacia do Rio Miringuava, São José dos Pinhais, Paraná.

\begin{tabular}{lccc}
\hline \multirow{2}{*}{ Classe do uso do solo } & \multirow{2}{*}{ Classe } & \multicolumn{2}{c}{ Área } \\
\cline { 3 - 4 } Campo & & Hectare & Porcentagem \\
\cline { 3 - 4 } Cultura permanente & & $1.121,91$ & 6,96 \\
Cultura temporária & Área não & 14,08 & 0,09 \\
Solo exposto & restrita & 1024,93 & 18,75 \\
Vegetação arbórea & & 276,67 & 0,63 \\
plantada & & $11.590,65$ & 1,72 \\
Áreas inaptas & Área restrita & $16.130,32$ & 11,86 \\
\hline Total & & &
\end{tabular}

FONTE: Autores (2018)

Do percentual restante da área de estudo representada por área não restrita (4.539,67 ha), a classe de uso do solo "Cultura temporária" foi a que se mostrou-se distribuída de forma mais homogênea e predominante espacialmente, somando uma área de 3.024,93 ha. Por outro lado, a classe de "Cultura permanente" é a que se apresentou em menor área total (14,08 ha), distribuída na porção mais ao oeste da área de estudo.

Estudos da determinação de áreas não aptas conforme análise espacial de classes de uso e ocupação do solo por meio das ferramentas do SIG são usuais no meio florestal e tem função relevante no melhor uso dos recursos naturais (PEDRON et al., 2006), o entrecruzamento entre os dados permite a geração de mapas 
contendo informações que se constituem um importante instrumento à análise de decisão (URBAN; ISAAC, 2016) como pode ser verificado no presente estudo.

Conforme expõe a Figura 5, é possível observar que do total de área apta pelo uso do solo (Tabela 4), a microbacia foi dividida em quatro classes de declividade em nível de dificuldade de movimentação das máquinas florestais. Percebe-se que cerca de $2 \%(107,74$ ha) desta área mostrou-se restrita para implantação de povoamentos florestais, por apresentar declividade maior que $45^{\circ}$, considerada área de preservação ambiental (APP) pela Lei 12.651. Por outro lado, cerca de $73 \%$ (3.310,21 ha), da área ideal conforme o uso do solo, apresenta baixa inclinação de 0 a $10^{\circ}$, indicando um alto potencial para o uso florestal da área de estudo.

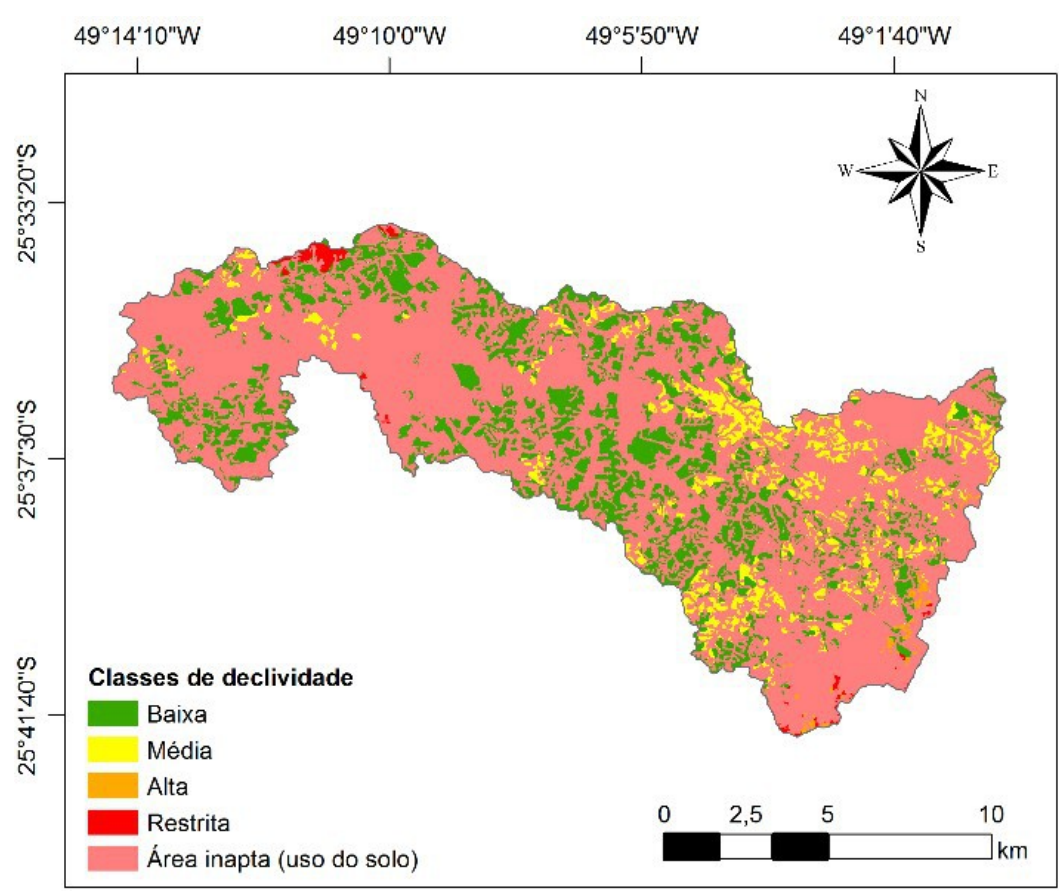

FIGURA 5. Representação espacial das classes de declividade quanto a aptidão para um plantio florestal, na microbacia do Rio Miringuava, São José dos Pinhais, Paraná.

FONTE: Autores (2018)

TABELA 4. Área das classes de declividade quanto a aptidão para um plantio florestal, na microbacia do Rio Miringuava, São José dos Pinhais, Paraná.

\begin{tabular}{lccc}
\hline Classe de & Intervalo de & \multicolumn{2}{c}{ Área } \\
\cline { 3 - 4 } declividade & inclinação & Hectare & Porcentagem I \\
\hline Baixo & 0 a 10 & $3.310,21$ & 72,92 \\
Médio & 10 a 20 & $1.059,04$ & 23,33 \\
Alto & 20 a 45 & 62,68 & 1,38 \\
Restrito & $>45$ & 107,74 & 2,37 \\
Total & - & $4.539,67$ & 100,00 \\
\hline
\end{tabular}

FONTE: Autores (2018) 
É importante destacar que a superfície de inclinação é uma variável imprescindível em diversos estudos florestais, como por exemplo, determinação de áreas de fragilidade ambiental (TRAFICANTE et al., 2017; ALVES et al., 2017), áreas ideais para implantação de estradas (DEMIR, 2007; EMMERT et al., 2010) e capacidade de uso do solo (FLAUZINO et al., 2016). Muitas vezes, neste tipo de estudos, a inclinação é a informação analisadas em prioridade por se constituir um atributo crítico do terreno com consequências indesejáveis.

Conforme o ponto de localização da fábrica hipotética foi efetuada a classificação de 4 classes de custo de distância com base nas classes de uso do solo e declividade (Figura 6). A zona de menor custo apresentou uma área de $2.532,54$ ha, representando percentual de $15,76 \%$ da área total da microbacia de Miringuava. Sendo que a zona de maior extensão em área (5.932,37 ha) foi a classe de médio custo de distância. E classe de maior custo de distância foi a de menor extensão (Tabela 5).

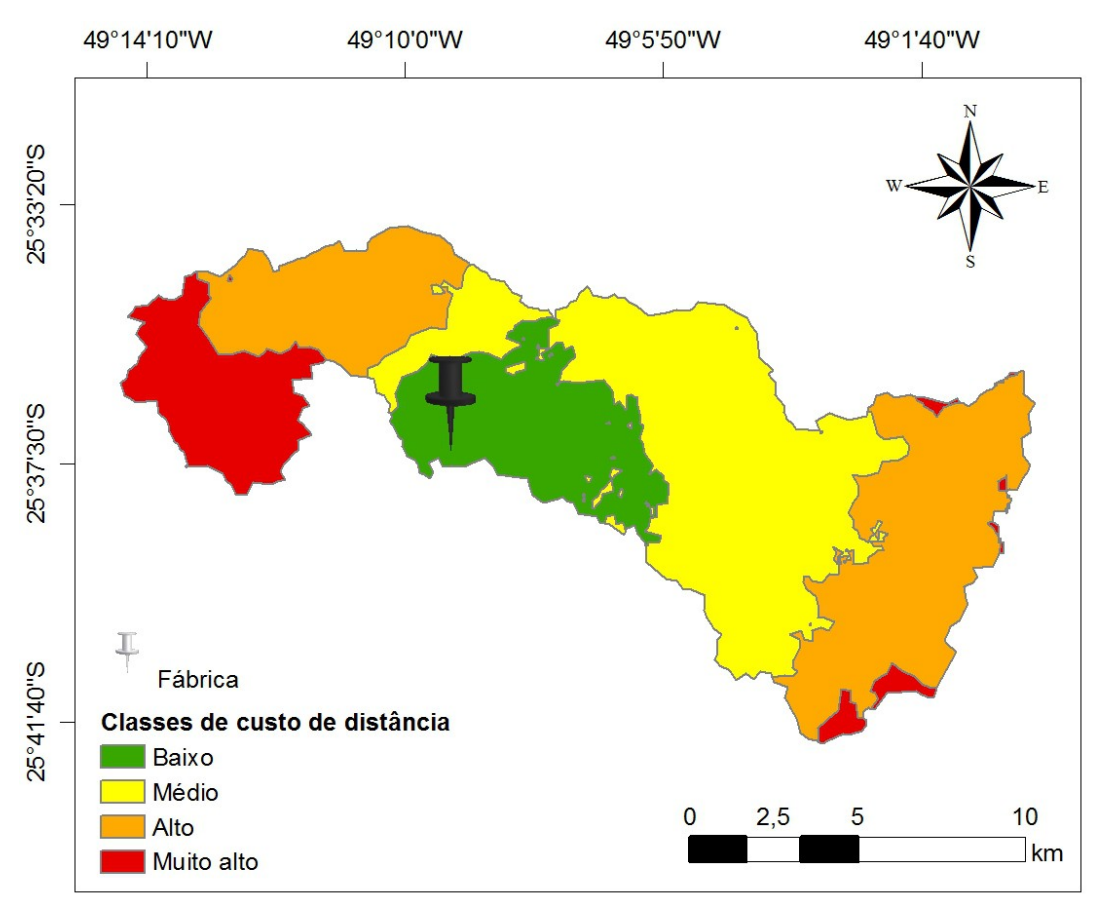

FIGURA 6. Representação das classes de custo de distância da fábrica de acordo com a superfície de áreas aptas conforme o uso do solo e declividade ideal para um plantio florestal, na microbacia do Rio Miringuava, São José dos Pinhais, Paraná.

FONTE: Autores (2018)

TABELA 5. Área das classes de custo de distância da fábrica de acordo com a superfície de áreas aptas conforme o uso do solo e declividade ideal para um plantio florestal, na microbacia do Rio Miringuava, São José dos Pinhais, Paraná.

Classes de custo de distância

Área

Baixo

\begin{tabular}{cc}
\hline Hectare & Porcentagem \\
\hline $2.532,54$ & 15,76
\end{tabular}

Médio

$5.932,37$

36,92

Alto

$5.576,85$

34,70

Muito alto

$2.028,18$

12,62 


\begin{tabular}{lcc}
\hline Total & $16.069,94$ & 100,00 \\
\hline FONTE: Autores (2018)
\end{tabular}

FONTE: Autores (2018)

A preocupação sobre a localização de povoamentos a serem manejadas, isto é a distância até a fábrica, já foi considerado em alguns trabalhos como o de Lopes et al. (2016) e Gomes et al. (1998), nas quais os autores convergem na afirmação que esta informação tem influência direta nos custos finais da produção devido ao efeito significativo dos custos de transporte. Em que, conforme Rodrigues (2014) o custo logístico de transporte chega a $60 \%$ em média na maioria das empresas transportadoras.

Por fim, a Figura 7 mostra espacialmente as 10 classes finais que foram geradas considerando o cruzamento das variáveis uso do solo, declividade e o custo de distância. E a Tabela 3 mostra a área em hectares destas classes. Na classe custo de distância baixo, obteve-se áreas com duas classes de declividade (baixa e média) que são as melhores classes para seleção do plantio por abranger as áreas de declividade até $20^{\circ}$, zona de baixo custo de distância, nas quais totalizam 826,14 ha, que representa 18,64 \% da área total apta conforme as três variáveis.

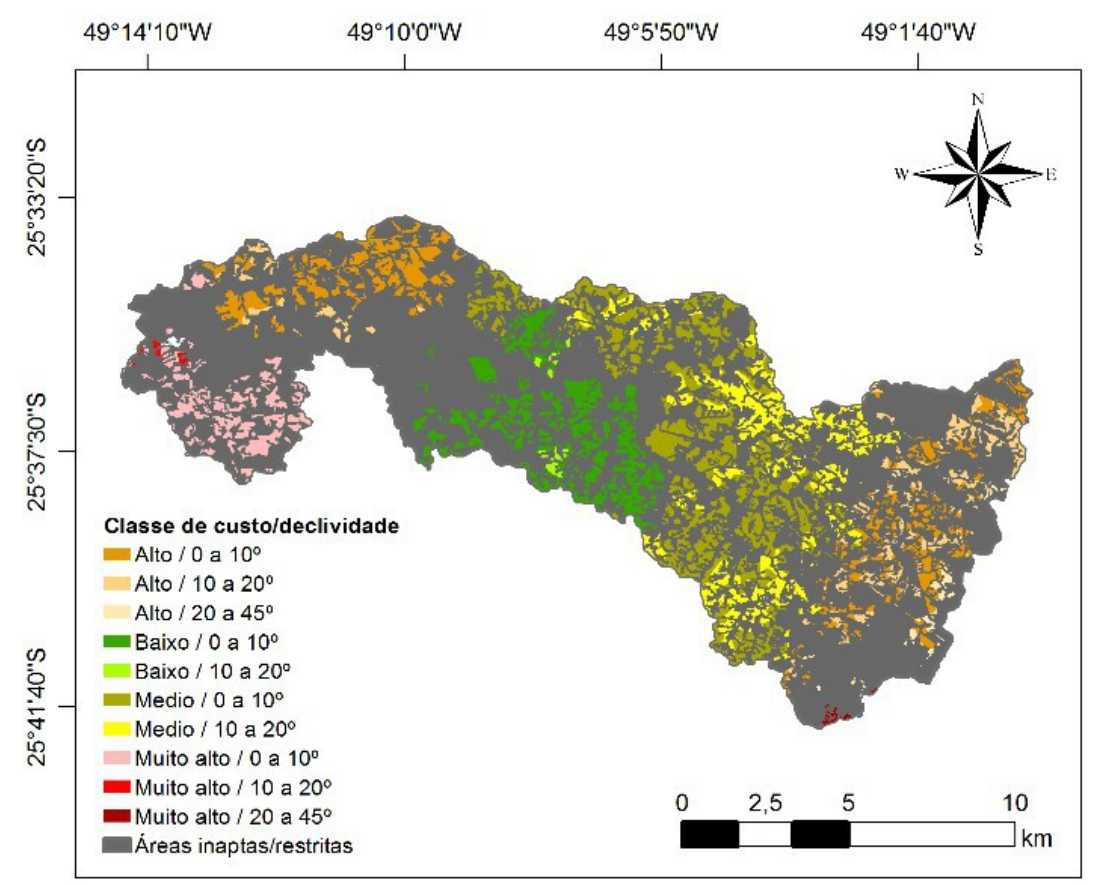

FIGURA 7. Classificação do custo de distância e declividade quanto a aptidão para um plantio florestal, na microbacia do Rio Miringuava, São José dos Pinhais, Paraná.

FONTE: Autores (2018)

Diante este resultado é possível inferir que em caso de necessidade de até 793,23 ha deve ser selecionado inicialmente da classe 1 . No caso de necessidade maior área deve ser escolhida nas classes seguintes até a classe 10 , respectivamente.

É possível perceber que a classe de custo de distância em maior área se encontra na de custo médio, em específico na declividade baixa. Enquanto que a classe de custo de distância muito alto em declividade alta apresenta-se a menor em 
área. Observa-se que as duas melhores classes de custo de distância (baixo e médio) não apresentaram classes de declividade alta.

Diversas literaturas encontraram também resultados satisfatórios em análises de áreas florestais considerando alguns critérios do terreno por meio de SIG. Nas quais, podem-se citar o trabalho de Lima et al. (2011) que encontrou locais ótimos para realizar o empilhamento de toras de eucalipto, Emmert et al. (2010) que determinou áreas críticas para transporte de madeira, Akgul et al. (2017) que que efetuou a medição da degradação de estradas florestais.

TABELA 3. Área das classes ideias para implantação de povoamentos florestais, na microbacia do Rio Miringuava, São José dos Pinhais, Paraná.

\begin{tabular}{|c|c|c|c|}
\hline $\mathrm{N}^{\circ}$ classe & $\begin{array}{l}\text { Custo de } \\
\text { distância }\end{array}$ & Declividade $\left({ }^{\circ}\right)$ & Área (ha) \\
\hline 1 & \multirow{3}{*}{ Baixo } & Baixa (0 a 10) & 793,23 \\
\hline 2 & & Médio (10 a 20) & 32,91 \\
\hline Subtotal & & - & 826,14 \\
\hline 3 & \multirow{3}{*}{ Médio } & Baixa (0 a 10) & $1.330,40$ \\
\hline 4 & & Médio (10 a 20) & 647,89 \\
\hline Subtotal & & - & $1.978,29$ \\
\hline 5 & \multirow{4}{*}{ Alto } & Baixa (0 a 10) & 827,09 \\
\hline 6 & & Médio (10 a 20) & 364,11 \\
\hline 7 & & Alta (20 a 45) & 51,31 \\
\hline Subtotal & & - & $1.242,51$ \\
\hline 8 & \multirow{4}{*}{ Muito alto } & Baixa (0 a 10) & 359,5 \\
\hline 9 & & Médio (10 a 20) & 14,13 \\
\hline 10 & & Alta (20 a 45) & 11,37 \\
\hline Subtotal & & - & 385 \\
\hline & Total & - & $4.431,93$ \\
\hline
\end{tabular}

FONTE: Autores (2018)

É importante destacar que o presente trabalho utilizou dados oriundos do AGUASPARANÁ (2018) e ITCG (2018), os quais se encontravam previamente georreferenciados, o que permitiu uma maior praticidade e redução de tempo de processamento. Além disso, observa-se que a metodologia do presente trabalho permite a atribuição de novas variáveis, bem como, diferentes classes e pesos para complementar a pesquisa, conforme a necessidade e a realidadee demanda recorrente pelos de usuários. 


\section{CONCLUSÃO}

A metodologia do presente estudo permitiu identificar que a maior parte da área do estudo $(71,85 \%)$ foi considerada inapta pelo uso do solo e apenas $18,64 \%$ da área foi considerada a mais indicada para plantios florestais conforme as variáveis utilizadas. Os resultados deste trabalho mostram que foi possível selecionar as áreas aptas para implantação de povoamentos florestais de forma ágil e concisa para o Estado do Paraná, viabilizada pelo uso de SIG e dados préprocessados.

\section{AGRADECIMENTOS}

Agradecimentos ao Instituto Águas Paraná - AGUASPARANÁ e institucional do Instituto de Terras, Cartografia e Geologia do Paraná - ITCG por conceder os dados referentes a área de estudo utilizados para alcançar o objetivo do presente estudo; e a Coordenação de Aperfeiçoamento de Pessoal de Nível Superior (CAPES) e o Conselho Nacional de Desenvolvimento Científico e Tecnológico (CNPq) pela concessão de bolsa aos autores pós-graduandos.

\section{REFERÊNCIAS}

AKGUL, M.; YURTSEVEN, H.; AKBURAK, S.; DEMIR, M.; CIGIZOGLU, H. K.; et al. Short term monitoring of forest road pavement degradation using terrestrial laser scanning. Measurement, v. 103, p. 283-293, 2017. Disponível em: < https://doi.org/10.1016/j.measurement.2017.02.045 >. 10.1016/j.measurement.2017.02.045

ALVES, R. T.; FIEDLER, N. C.; SILVA, E. N. D.; LOPES, E. D. S.; CARMO, F. C. D. A. D. Análise técnica e de custos do transporte de madeira com diferentes composições veiculares. Revista Árvore, v. 37, n. 5, 2013. Disponível em: <http://dx.doi.org/10.1590/S0100-67622013000500012>. d doi:10.1590/S010067622013000500012

ALVES, W. S.; SCOPEL, I.; MARTINS, A. P. Análise da fragilidade ambiental da Bacia do Ribeirão das Abóboras, em Rio Verde, Sudoeste de Goiás. Revista Internacional de Ciencia y Tecnología de la Información Geográfica, n. 19, p. 81-108, 2017. Disponível em: <http://dx.doi.org/10.21138/GF.556>. doi:10.21138/GF.556

APRE - Associação Paranaense de Empresas de Base Florestal . Estudo Setorial 2017/2018. Curitiba: APRE, 2018. Disponível em: <http://www.apreflorestas.com.br/wp-content/uploads/2018/02/Estudo-Setorial2018_APRE.pdf>. Acesso em: 24 abr. 2018.

DEMIR, M. Impacts, management and functional planning criterion of forest road network system in Turkey. Transportation Research Part A: Policy and Practice, v. $41, \quad$ n. $1, \quad$ p. 56-68, 2007. Disponível em: <https://doi.org/10.1016/j.tra.2006.05.006>. doi: 10.1016/j.tra.2006.05.006 
RODRIGUES, P. R. Introdução aos sistemas de transporte no Brasil e à logística internacional. São Paulo: Aduaneiras, 5.ed., 2014. 248 p.

EMMERT, F.; PEREIRA, R. S.; REZENDE, A. V.; IMAÑAS ENCINAS, J. M. Geoprocessamento como ferramenta de apoio à gerência de pavimentos em estradas florestais. Ciência Florestal, v. 20, n. 1, 2010. Disponível em: < https://doi.org/10.5902/198050981763> doi: 10.5902/198050981763

ESRI - Environmental Systems Research Institute . 2018. ArcGIS Desktop: Understanding cost distance analysis. Disponível em: $<$ http://desktop.arcgis.com/en/analytics/case-studies/understanding-cost-distanceanalysis.htm>. Acesso em: 11 jan. 2018.

FERREIRA, F. D. A. C.; DA SILVA LEITE, E.; DE FREITAS, L. C.; DAS VIRGENS, A. P. Potencial de krigagem em modelos digitais de elevação para o planejamento da colheita florestal. Pesquisa Florestal Brasileira, v. 37, n. 92, p. 579-586, 2017. Disponível em: <https://doi.org/10.4336/2017.pfb.37.92.1492>. doi: 0.4336/2017.pfb.37.92.1492

FLAUZINO, B. K.; MELLONI, E. G. P.; PONS, N. A. D. Mapeamento da capacidade de uso da terra como contribuição ao planejamento de uso do solo em sub-bacia hidrográfica piloto no Sul de Minas Gerais. Geociências, v. 35, n. 2, p. 277-287, 2016. Disponível em < http://www.ppegeo.igc.usp.br/index.php/GEOSP/article/view/9025/8290>. Acesso em: 05 fev. 2018.

GOMES, F. S.; MAESTRI, R.; SANQUETTA, C. R. Análise financeira de regimes de manejo em povoamentos de Pinus taeda L., visando à produção de madeira para a indústria de papel e celulose. Revista árvore, v. 22, n.2, p. 227-243, 1998.

IBA - Indústria Brasileira de Árvores. Relatório IBÁ 2017. Brasília: IBÁ, 2017. Disponível em: http://iba.org/images/shared/Biblioteca//BA_RelatorioAnual2017.pdf>. Acesso em: 14 jan. 2018.r

AGUASPARANÁ - Instituto das águas do Paraná. 2018. Dados para Download. Disponível em:

http://www.aguasparana.pr.gov.br/modules/conteudo/conteudo.php?conteudo=79>. Acesso em: 10 jan. 2018.

ITCG - Instituto de terras, cartografia e geografia do Paraná. 2018. Dados e informações geoespaciais temáticos. Disponível em: < http://www.itcg.pr.gov.br/modules/faq/category.php?categoryid=9\#>. Acesso em: 08 jan. 2018.

LEITE, E. S.; FERNANDES, H. C.; MINETTE, L. J.; DE SOUZA, A. P.; GARCIA LEITE, H.; LUIZ GUEDES, I. Modelagem do desempenho da extração de madeira pelo "forwarder". Revista Árvore, v. 38, n. 5, p. 879-887, 2014. Disponível em: <http://dx.doi.org/10.1590/S0100-67622014000500012>. doi:10.1590/S010067622014000500012 
LIMA, M. P. D.; CARVALHO, L. M. T. D.; MARTINHAGO, A. Z.; OLIVEIRA, L. T. D.; CARVALHO, S. D. P. C.; et al. Methodology for planning log stacking using geotechnology and operations research. Cerne, v. 17, n. 3, p. 309-319, 2011. Disponível em: <http://dx.doi.org/10.1590/S0104-77602011000300004>. doi: $10.1590 / \mathrm{S} 0104-77602011000300004$

LOPES, E. S.; VIEIRA, T. P.; RODRIGUES, C. K. Avaliação técnica e de custos do transporte rodoviário com diferentes espécies e sortimentos de madeira. Floresta, v. 46, n. 3, p. 297-306, 2016. Disponível em: < http://dx.doi.org/10.5380/rf.v46i3.36826>. doi:10.5380/rf.v46i3.36826

MACHADO, C. C. Colheita Florestal. Editora UFV, $3^{a}$ edição, Viçosa, 2014. 543 p.

PEDRON, F. A.; POELKING, E. L.; DINIZ DALMOLIN, R. S.; AZEVEDO, A. C.; KLAMT, E. A aptidão de uso da terra como base para o planejamento da utilização dos recursos naturais no município de São João do Polêsine-RS. Ciência Rural, v. 36, n. 1, p. 105-112, 2006. Disponível em: <http://dx.doi.org/10.1590/S010384782006000100016>. doi:10.1590/S0103-84782006000100016

ROCHA, E. S.; BARROS, P. L. C.; NAZARÉ MACIEL, M. Avaliação da densidade ótima de estradas florestais em dois sistemas de exploração florestal no Estado do Pará. Revista de Ciências Agrárias/Amazonian Journal of Agricultural and Environmental Sciences, v. 47, n. 1, p. 49-58, 2011. Disponível em: <https://btcc.ufra.edu.br/index.php/ajaes/article/view/193>. Acesso em: 20 fev. 2018.

SNIF - Sistema Nacional de Informações Florestais. Boletim SNIF 2017. Brasília: SNIF, 2017. Disponível em: http://www.florestal.gov.br/documentos/publicacoes/3230-boletim-snif-2017-ed1final/file>. Acesso em: 15 jan. 2018.

SUDERHSA-PR - Superintendência e Desenvolvimento de Recursos hídricos e saneamento ambiental do parana. Uso do solo - Bacia do Alto Iguaçu. Curitiba, 2000. Escala 1:20.000. Disponível em: <http://www.aguasparana.pr.gov.br/modules/conteudo/conteudo.php?conteudo=92>. Acesso em: 11 jan. 2018.

TRAFICANTE, D.; POLIZELI, D. P.; CAMPOS, S.; MANZIONE, R. L.; RODRIGUES, B. T. Fragilidade ambiental da Bacia Hidrográfica do Rio Capivara, Botucatu-SP. Energia na Agricultura, v. 32, n. 1, p. 88-95, 2017 . Disponível em: <http://dx.doi.org/10.17224/EnergAgric.2017v32n1p88-95>. doi:10.17224/EnergAgric.2017v32n1p88-95

URBAN, R.C.; ISAAC, R.L. Mapa de aptidão do solo para a aplicação de lodo de esgoto: Bacia dos rios Piracicaba, Capivari e Jundiaí. Revista Ambiente \& Água, v.11, n.1, p. 125-134, 2016. <https://doi.org/10.4136/ambi-agua.1714>. doi:10.4136/ambi-agua. 1714 